Louisiana State University

LSU Digital Commons

Faculty Publications

Department of Biological Sciences

$1-1-2004$

\title{
Comment on "Molecular phylogenies link rates of evolution and speciation" (I).
}

Christopher C. Witt

Louisiana State University

Robb T. Brumfield

Louisiana State University

Follow this and additional works at: https://digitalcommons.Isu.edu/biosci_pubs

\section{Recommended Citation}

Witt, C., \& Brumfield, R. (2004). Comment on "Molecular phylogenies link rates of evolution and speciation" (I).. Science, 303 (5655) https://doi.org/10.1126/science.1089822

This Article is brought to you for free and open access by the Department of Biological Sciences at LSU Digital Commons. It has been accepted for inclusion in Faculty Publications by an authorized administrator of LSU Digital Commons. For more information, please contact ir@lsu.edu. 


\section{Comment on "Molecular Phylogenies Link Rates of Evolution and Speciation" (I)}

Webster et al. (1) reported an association between rates of speciation and molecular evolution, suggesting that speciation is often accompanied by Mayrian genetic revolutions, or molecular punctuated equilibria. This important finding has been hinted at in previous studies (2). However, the conclusions of Webster et al. are compromised by three factors: (i) potentially insufficent correction for the node density effect, (ii) underestimation of speciation rate due to sparse taxon sampling, and (iii) phylogenetic nonindependence among data sets.

The node density effect, which is primarily a result of saturation, causes rates of speciation and evolution to appear correlated. To identify and exclude from their analysis data sets suffering from this effect, Webster et al. plotted the number of nodes $(n)$ along a path against the length of that path from root to tip $(x)$ for each of their 56 phylogenies. They fit this data to the function $n=x^{\delta}$, and discarded the 13 phylogenies for which $\delta>1$. Although path length is usually expressed as a function of the number of nodes $(3,4)$, it is important to note that Webster et al. reversed this relationship. Under their scenario, when $\delta>1$, path length increases with increasing node density, but only until additional nodes no longer reveal additional change. This pattern merely suggests that taxon sampling is sufficiently dense to reveal all molecular change in some parts of the tree, but not in others. It could result from excess sampling among closely related taxa at the tips of the tree. Although $\delta>1$ implicates saturation, $\delta \leq 1$ does not imply an absence of saturation. Fitch and Bruschi demonstrated this point in figure $1 \mathrm{~A}$ in (3), which showed a strictly linear relationship between path length and node density. Any positive correlation between node number and path length is consistent with saturation, which affects nearly all molecular data sets. The node density effect potentially affects all 56 phylogenies, and may have led Webster et al. to infer rapid evolution in species-rich clades.

Additional bias stems from the potential for incorrect topology. Well-resolved molecular phylogenies are rare, and probably few, if any, of the 56 phylogenetic hypotheses are completely consistent with the true underlying phylogenies. An incorrect node on a given path could artificially increase the inferred amount of molecular evolution on that path. The well-known tendency for long branches to be erroneously linked could compound the node density effect $(5,6)$.

Sparse taxon sampling prevents accurate inference of the number of speciation events along a lineage. Webster et al. included higherlevel phylogenies that sampled, for example, $0.3 \%$ of birds, 0.4 to $1.4 \%$ of mammals, 0.01 to $0.005 \%$ of plants, and $0.002 \%$ of insects. In these phylogenies, the number of speciation events inferred for each total path could be underestimated by orders of magnitude. Twentyone of the 56 phylogenies sampled fewer than two taxa per genus. The recent finding that tree shape varies according to the taxonomic level sampled (7) indicates that higher level phylogenies are misleading with respect to relative rates of cladogenesis. Furthermore, Webster et $a l$. used virus, bacteria, and population genetic data sets in which the interpretation of nodes as speciation events is questionable. Species limits should be defined a priori in studies of speciation rate.

Webster et al. controlled for phylogenetic non-independence within each phylogeny, but many of their 56 phylogenies sampled the same taxa. Five phylogenies were composed of overlapping sets of mammalian families and orders, and others contained identical sets of plant taxa, but different genes. Statistical meta-analysis of these phylogenies suffered from phylogenetic nonindependence.

We recommend calculating relative rates of evolution using independent pairwise distances, rather than phylogenetically estimated path lengths. However, only phylogenies that are thoroughly sampled at the species level should be used to estimate the number of nodes on each path.

Christopher C. Witt Department of Biological Sciences and Museum of Natural Science Louisiana State University Baton Rouge, LA 70803, USA

E-mail:cwitt@lsu.edu

Robb T. Brumfield Museum of Natural Science Louisiana State University

References and Notes

1. A. J. Webster, R. J. H. Payne, M. Pagel, Science 301, 478 (2003).

2. T. G. Barraclough, V. Savolainen, Evolution 55, 677 (2001).

3. W. M. Fitch, M. Bruschi, Mol. Biol. Evol. 4, 381 (1987).

4. W. M. Fitch, J. J. Beintema, Mol. Biol. Evol. 7, 438 (1990).

5. J. Felsenstein, Syst. Zool. 27, 401 (1978).

6. M. J. Sanderson, J. A. Doyle, Am. J. Bot. 88, 1499 (2001).

7. A. Purvis, P.-M. Agapow, Syst. Biol. 51, 844 (2002).

8. We thank K. Naoki, F. H. Sheldon, and S. M. Witt for helpful discussion.

30 July 2003; accepted 23 September 2003 


\section{Science}

Comment on "Molecular Phylogenies Link Rates of Evolution and Speciation" (I)

Christopher C. Witt, and Robb T. Brumfield

Science, 303 (5655),

View the article online

https://www.science.org/doi/10.1126/science.1089822

Permissions

https://www.science.org/help/reprints-and-permissions 